\title{
Selective Solid-Phase Extraction of Meropenem from Human Blood Plasma Using a Molecularly Imprinted Polymer
}

\author{
Lasmaryna Sirumapea ${ }^{1,2^{\star}}$, Muhammad Ali Zulfikar ${ }^{1}$, Muhammad Bachri Amran $^{1}$, and Anita Alni ${ }^{1}$ \\ ${ }^{1}$ Department of Chemistry, Faculty of Mathematics and Natural Sciences, Bandung Institute of Technology, \\ Jl. Ganesha No. 10, Bandung 40132, West Java, Indonesia \\ ${ }^{2}$ STIFI Bhakti Pertiwi Palembang, Jl. Ariodillah III No. 22, Palembang 30128, South Sumatera, Indonesia
}

\section{*Corresponding author:}

email:lasmaryna2906@gmail.com

Received: February 11, 2021

Accepted: June 10, 2021

DOI: $10.22146 /$ ijc. 64025

\begin{abstract}
This study employed a selective and high adsorption performance for meropenem. Molecularly imprinted polymer for meropenem (MeIP) as the selective sorbent was prepared through a bulk polymerization reaction. Methacrylic acid, ethylene glycol dimethacrylate, benzoyl peroxide, and dimethyl sulfoxide were applied as functional monomer, crosslinker agent, initiator, and solvent, respectively. Scanning electron microscopy, thermogravimetric analysis, Brunauer-Emmett-Teller analysis, and Fourier transform infrared spectroscopy were used to characterize the morphology, pore size, and structure of imprinted polymers. The maximum adsorption capacity was achieved at $p H$ $=3$, after $4 \mathrm{~h}$ contacted, under $150 \mathrm{rpm}$, and $25 \mathrm{mg}$ of polymer applied. The maximum adsorption capacity of MeIP for meropenem was $51.963 \mathrm{mg} / \mathrm{L}$; the synthesized polymer had superior selectivity to meropenem compared to that of the other antibiotics (imprinting factor, IF = 2.58). Furthermore, the thermodynamic and kinetic analyses indicated that the results were in accord with the Freundlich model and the pseudo-second-order kinetic model, respectively. MeIP was selective in batch adsorption, and molecularly imprinted solid-phase extraction protocols were selective to meropenem. It was then applied to analyze meropenem in human blood plasma and resulted in $78.52 \pm 2.71$ of recovery.
\end{abstract}

Keywords: meropenem; molecularly imprinted polymer; selective; solid-phase extraction

\section{- INTRODUCTION}

Meropenem, chemically $(4 R, 5 S, 6 S)-3-[(3 S, 5 S)-5-$ (dimethylcarbamoyl)pyrrolidin-3-yl]sulfanyl-6-[(1R) -1hydroxyethyl]-4-methyl-7-oxo-1-azabicyclo[3.2.0] hept2-ene-2-carboxylic acid, is a broad-spectrum antibacterial agent from the carbapenem family, with a $\beta$-lactam ring on its main structure [1]. Meropenem is commonly used in a therapy or a treatment of infection or disease in both adults and children that is caused by single or multiple susceptible bacteria [2]. For intravena protocols, meropenem was found in human blood plasm at 23 $\mu \mathrm{g} / \mathrm{mL}$ and $49 \mu \mathrm{g} / \mathrm{mL}$ after $30 \mathrm{~min}$ of injection for the dose of $500 \mathrm{mg}$ and $1,000 \mathrm{mg}$ respectively [3]. Currently, the misuse of antibiotics is becoming a great concern along with drug resistance arising in the target of a treated microorganism. There are several reports regarding the build-up of resistance to antibiotics by microorganisms, highlighting a decline of antibiotic efficiency unless a more rational and controlled use of such compounds is established [4]. Some methods mostly based on UV and MS detection have been developed to quantify antibiotics in different matrices. The determination of antibiotics in liquid samples has been reported, which commonly used the solid-phase extraction (SPE) method [5-7]. SPE was favorable recently because of its simplicity, short time procedure and minimal of solvent consuming. The development of sample pretreatment of antibiotics, especially meropenem, using, for example, SPE and column switching methods have been reported to be due to the combination of SPE-chromatography for the determination of some kinds of medicine [8]. However, the extraction of antibiotics as analytes using the SPE method is rather difficult due to the lack of 
selectivity. Recently, the use of a molecularly imprinted polymer (MIP), synthesized using the molecular imprinting method, as a sorbent has been evolved to enhance the high selectivity of SPE (MI-SPE). The MIPs use the functionality of a target molecule (template) by forming specific interactions with a matrix during polymerization to assemble their own recognition site. The mechanism involves the formation of interaction or bonds by the template molecule, and the functional element before locking-in or bonds then drives the formation of a matrix with a selective recognition site for the template [9]. Because of its specific recognition and high selectivity, MIP has been applied as a potential cleanup system in many different sample matrices. MI-SPE also exhibits other favorable properties such as low cost, high stability, reusability, and long-term storage [10-11]. Highly selective sorbents toward a large number of analytes of environmental and pharmaceutical interests can be prepared by molecular imprinting.

This study presented the preparation of meropenem imprinted polymer (MeIP), through bulk polymerization, using methacrylic acid (MA) as a functional monomer, ethylene glycol dimethacrylate (EGDMA) as a crosslinker, benzoyl peroxide (BPO) as an initiator, dimethyl sulfoxide (DMSO) as a porogenic solvent and meropenem (Merp) as a template molecule. The aim of this work was to find the selective adsorbent of SPE for meropenem identification in human blood plasma. The morphology and structure of MeIP were characterized using scanning electron microscopy (SEM), Fourier transform infrared spectroscopy (FTIR), and thermogravimetric analysis; pores and the surface were analyzed using BrunauerEmmett-Teller (BET). The adsorption characteristics of MeIP were also investigated. Then, it was coupled with high-performance liquid chromatography (HPLC); MeIP was employed for SPE and applied to determine the amount of meropenem in spiked human blood plasma. A polymer synthesis from MA, EGDMA, and DMSO as solvents had not been reported previously.

\section{- EXPERIMENTAL SECTION}

\section{Materials}

The chemicals used in this study were meropenem trihydrate purchased from Bernofarm Laboratories Company, MA, acrylamide (Sigma Aldrich), EGDMA, DMSO and BPO. Acetic acid (Merck Chemicals), nitrogen gas, methanol, acetonitrile (Fulltime Chemicals), curcumin, cefadroxil, amoxicillin and penicillin G (Kalbe Farma) were also used. While the distilled water was purchased based on HPLC grade.

\section{Instrumentation}

The Thelco Laboratory model 130D heater was used for polymer synthesis; FTIR (Shimadzu Prestige 21) was used to investigate the functional groups of polymers; UV-visible spectrophotometer (Agilent 8453 G1103A); scanning electronic microscope (Hitachi SU 3500); HPLC (Infinity Agilent Tech. 1260 series), was set at 298 and $309 \mathrm{~nm}$; Restek column for chromatography (C-18 150x4,6); BET (NOVA-Quntrachrome Instruments 10.01) was used to analyze the surface area, pore size, and pore diameter; SPE procedure was carried out using Supelco Visiprep ${ }^{\mathrm{TM}}$ 24; thermogravimetric analysis was performed using NETZSCH STA 449 F1; shaker and $\mathrm{pH}$ meter.

\section{Procedure}

\section{Preparation of MIP, NIP, and MeIP}

For the preparation of MIP, $0.5 \mathrm{mmol}$ meropenem, and $5 \mathrm{mmol}$ MA were dissolved in $15 \mathrm{~mL}$ DMSO. They were contacted for approximately $15 \mathrm{~min}$, in the prepolymerization process at room temperature and without velocity on shaking procedure. Then, $20 \mathrm{mmol}$ EGDMA was added to the solution, followed by water sonication, and $\mathrm{N}_{2}$ gas was streamed into the mixture for approximately $10 \mathrm{~min}$. A polymer solution was heated at $65{ }^{\circ} \mathrm{C}$ for $4 \mathrm{~h}$. After the polymerization completed and produced MIP. MIP was then separated from excess of solvent, dried at $65-70{ }^{\circ} \mathrm{C}$. The templates were extracted from the polymer by soxhlation where a mixture of methanol:acetic acid $(87.5: 12.5 \mathrm{v} / \mathrm{v})$ was used as the solvent to construct MeIP. The extraction was controlled using a UV spectrophotometer at $\lambda=298-300 \mathrm{~nm}$ and HPLC at $\lambda=298 \mathrm{~nm}$ to ensure that the template molecules were totally extracted from the polymer. A non-imprinted polymer (NIP) was synthesized with the same composition and procedure of producing MIP in 
the absence of the analyte (meropenem). Adsorption of meropenem was done under batch adsorption process and also for continuous protocols to extract meropenem from human blood plasm through SPE cartridge.

\section{Characterization of polymers}

The functional group and structure in MIP, NIP and MeIP were observed using an FTIR spectrophotometer from 4,000 to $500 \mathrm{~cm}^{-1}$; morphology of the polymers was also observed using SEM with 2,000 times of magnitude for each polymer. Thermal analysis of polymers was carried out at a heating rate of $10^{\circ} \mathrm{C} / \mathrm{min}$ from room temperature to $800{ }^{\circ} \mathrm{C}$ under an air atmosphere. The specific pore diameter, surface area, and average pore diameter were measured by ANNOVA instruments with a bath temperature of $77.3 \mathrm{~K}$ and a nitrogen atmosphere.

\section{Adsorption test}

The stock solution of $1,000 \mathrm{mg} / \mathrm{L}$ of meropenem was prepared fresh daily before the analysis with distilled water of HPLC grade. The effect of $\mathrm{pH}$ on the adsorption capacity of the polymer was investigated by mixing the polymer with the analyte in a $0.03 \mathrm{M}$ phosphate buffer solution with a variation $\mathrm{pH}$ of 3 to 8 for $24 \mathrm{~h}$; a $40 \mathrm{~mL}$ $50 \mathrm{mg} / \mathrm{L}$ meropenem solution was mixed with $30 \mathrm{mg}$ of NIP and MeIP. The final concentration and capacity were then calculated using the Eq. (1) [12]:

$\mathrm{Q}=\mathrm{V}\left(\mathrm{C}_{0}-\mathrm{C}_{\mathrm{t}}\right) / \mathrm{m}$

where $\mathrm{Q}=$ adsorption capacity $(\mathrm{mg} / \mathrm{g}), \mathrm{C}_{0}=$ analyte concentration before adsorption $(\mathrm{mg} / \mathrm{L}), \mathrm{C}_{\mathrm{t}}=$ analyte concentration after adsorption $(\mathrm{mg} / \mathrm{L}), \mathrm{m}=$ mass of sorbent $(\mathrm{mg})$, and $\mathrm{V}=$ solution volume $(\mathrm{mL})$. Shaking rate was also observed by mixing a $30 \mathrm{mg}$ polymer with a $30 \mathrm{mg} / \mathrm{L}$ analyte solution in conical flask of $100 \mathrm{~mL}$ for $20 \mathrm{~h}$ at various rates: 100,150 and $200 \mathrm{rpm}$ at room temperature with a $0.03 \mathrm{M}$ phosphate buffer solution adjusted at $\mathrm{pH}=3$. The mass of polymer for adsorption was also observed by mixing a 20,25, 30,50,75, 100 and $125 \mathrm{mg}$ of polymer with a $50 \mathrm{mg} / \mathrm{L}$ analyte solution in a conical flask of $100 \mathrm{~mL}$ for $20 \mathrm{~h}$ with a $0.03 \mathrm{M}$ phosphate buffer solution at $\mathrm{pH}=3$. The effect of contact time (1$10 \mathrm{~h}$ ) was investigated by mixing a $50 \mathrm{mg} / \mathrm{L}$ analyte solution, $40 \mathrm{~mL}, 25 \mathrm{mg}$ of the polymer, then adsorption capacity was determined. Initial concentration was also studied with the variation of concentration applied were: $10,25,50,80,100$ and $125 \mathrm{mg} / \mathrm{L}$. Adsorption capacity was then determined. The adsorption capacity was then examined using a UV spectrophotometer. Selectivity was represented by the imprinting factor (IF) and selectivity coefficient $\alpha$, defined as $\mathrm{IF}=\mathrm{QMIP} / \mathrm{QNIP}$

and

$\alpha=\mathrm{IF}_{\text {analite }} / \mathrm{IF}_{\text {ana log molecule }}$

where QMIP is the adsorption capacity of MeIP, and QNIP is the adsorption capacity of NIP [12].

To investigate the adsorption kinetics, $25 \mathrm{mg}$ of polymer, $25 \mathrm{~mL}-40 \mathrm{mg} / \mathrm{L}$ of meropenem solution were placed into a conical flask. The mixture was shaken at $25^{\circ} \mathrm{C}$ at different time intervals $(60,120,180,240,300$, 360,480 , and $600 \mathrm{~min}$ ), and the concentration of meropenem in the supernatant was then analyzed.

\section{Molecularly imprinted solid-phase extraction procedure}

As much as $50 \mathrm{mg}$ of MeIP particles were packed into a $1 \mathrm{~mL}$ syringe as the cartridge and capped with a fritted polyethylene disk at the bottom. The cartridge was consecutively preconditioned with $2 \mathrm{~mL}$ distilled water and $2 \mathrm{~mL}$ methanol, followed by loading of $1 \mathrm{~mL}$ of the sample solution. After that, the cartridge was washed with acetonitrile:water $(95: 5 \mathrm{v} / \mathrm{v})$ and eluted with methanol: acetic acid $(80: 20 \mathrm{v} / \mathrm{v})$. The desorption solvent (methanol: acetic acid $=80: 20)$ gave a better percent adsorption value than (methanol:acetic acid $=90: 10 \mathrm{v} / \mathrm{v}$ ), but to maintain sorbent safety, an eluting solvent was chosen (methanol:acetic acid $=85: 15 \mathrm{v} / \mathrm{v}$ ). The flowrate was optimized with a variation of $0.25,0.55$, and $3.00 \mathrm{~mL} / \mathrm{min}$, then left for $5 \mathrm{~min}$, and left again for $10 \mathrm{~min}$. The concentration of the sample solution before and after its adsorption by the sorbent was analyzed using HPLC.

The optimization in SPE includes: the selection of conditioning solvents carried out on two types of solvents, namely methanol and methanol-water composition. Methanol provides a better percent recovery, so that methanol is chosen as the conditioning solvent. Furthermore, for the washing solvent the authors chose acetonitrile water $(95: 5 \mathrm{v} / \mathrm{v})$ with the approach that meropenem dissolves well in water. By 
selecting acetonitrile:water as the mobile phase, it is expected that meropenem will retain well in the sorbent, this is evidenced by the chromatogram produced after washing. For the elution stage, the same solvent as the desorbing solvent was chosen, which has been done previously.

\section{Sample preparation}

A fresh drug-free human plasma sample was obtained from the Indonesian Red Cross Organization, (PMI) Bandung-Indonesia. It was frozen, thawed, and allowed to reach room temperature before usage. To reduce matrices, blood plasma was diluted in methanol and then centrifuged at $6,000 \mathrm{rpm}$ at room temperature. Methanol fraction was taken for further use. As much as $1 \mathrm{~mL}$ of clean blood plasma spiked with $50 \mathrm{mg} / \mathrm{L}$ of meropenem in human plasma was allowed to pass the SPE column containing $50 \mathrm{mg}$ of sorbent MeIP. Plasma was considered as the diluent to dilute the meropenem solution. The flow rate was adjusted to $0.25 \mathrm{~mL} / \mathrm{min}$.

The filtrate then placed in a clear bottle and analyzed using HPLC. The adsorption and recovery were calculated following these equations:

$\%$ of adsorption $=\left(\mathrm{C}_{\text {intial }}-\mathrm{C}_{\mathrm{after}}\right) / \mathrm{C}_{\text {initial }} \times 100$

$\%$ recovery $=\mathrm{C}_{\text {found }} /\left(\mathrm{C}_{\text {initial }}-\mathrm{C}_{\text {after }}\right) \times 100$

$\mathrm{C}_{\text {initial }}$ is the concentration of the prepared analyte solution before its adsorption by MeIP, $\mathrm{C}_{\text {after }}$ is the concentration after adsorption by the polymer through the SPE column, and $\mathrm{C}_{\text {found }}$ is the concentration found after adsorption of the analyte by MeIP that was extracted from the polymer using a solution of methanol:acetic acid $(80: 20 \mathrm{v} / \mathrm{v})$.

\section{- RESULTS AND DISCUSSION}

\section{Synthesis of MIP, NIP, and MeIP}

The synthesis of MIP was carried out through bulk polymerization. This method was chosen because it is very simple, easy-prepared and no need of special treatment. DMSO was chosen as the solvent because it is an aprotic solvent that serves as porogen. The analyte has good solubility in water and DMSO. Although it has a high boiling point, the polymer should be dried before used. A previous study reported that a suitable porogen for noncovalent polymerization must be aprotic. The formation of interaction between monomer and the template are stabilized under hydrophobic environmental [13]. The MIP was yellow, and NIP was white because of no meropenem in its composition or backbone of the polymer. This work followed the noncovalent approach, where complete polymerization was followed by the process of crushing and sieving to small particle sizes from a macroporous polymer. The template was removed from the polymer by Soxhlet extraction with methanol:acetic acid (87.5:12.5 v/v) as the solvent for extraction. The extraction of meropenem was controlled periodically by measuring the amount of meropenem in the extraction solvent using a UV spectrophotometer until no analyte was found. The decrease of absorbance at 298-300 nm after time cycle of soxhlation means that the concentration of analyte (meropenem) was also decreased by the time. In Fig. 1, it can be seen that the specific peak of meropenem appeared at $300 \mathrm{~nm}$ (showed by the black line) meanwhile the red line shows that the peak was disappeared. Then it can be concluded that no more meropenem existed in the backbone of the polymer after the extraction. It means that meropenem has been successfully removed from the polymer, hence the polymer is ready to be used. The leached polymer particles were sieved to obtain particles with sizes between 60 and 80 mesh.

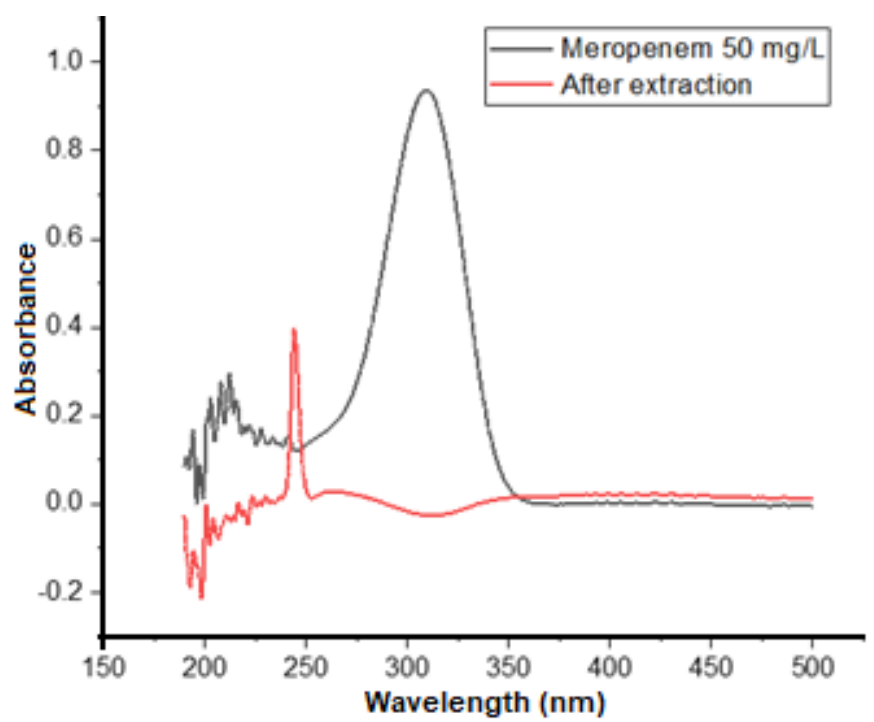

Fig 1. The spectrum of the analyte solution after analyte removal 

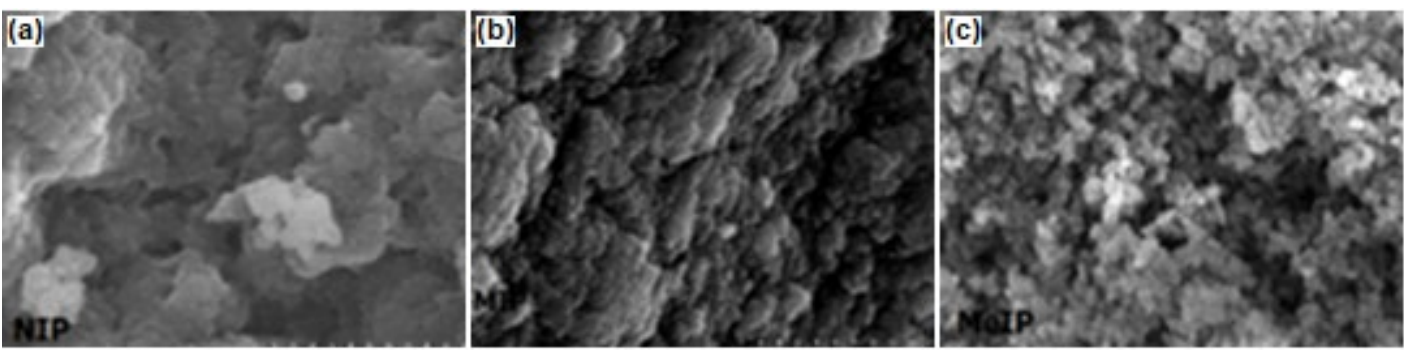

Fig 2. The morphology of (a) NIP, (b) MIP, and (c) MeIP characterized by SEM

Table 1. Adsorption capacity of NIP and MeIP

\begin{tabular}{ccccc}
\hline Sorbent & $\mathrm{C}_{0}, \mathrm{ppm}$ & $\mathrm{C}_{\mathrm{t}}, \mathrm{ppm}$ & $\mathrm{Q}, \mathrm{mg} / \mathrm{g}$ & $\mathrm{IF}$ \\
\hline MeIP & 25 & 18.3235 & 5.3412 & 2.589 \\
NIP & 25 & 22.4216 & 2.0627 & \\
\hline
\end{tabular}

To confirm the adsorption capacity of synthesized and extracted polymers, a batch-binding experiment was employed. As much as $30 \mathrm{mg}$ of polymers (MeIP and NIP) were placed in a $100 \mathrm{~mL}$ conical flask and mixed with 30 $\mathrm{mL}$ of the analyte solution $25 \mathrm{mg} / \mathrm{L}$ which diluted with demineralized water under room temperature. Table 1 presents that MeIP had higher adsorption capacity than NIP. When the selectivity equals to 1 , there is no adsorption capacity difference between MeIP and NIP. When the binding of MeIP > NIP, it indicates that MeIP has higher specific binding ability than NIP [14].

\section{Characterization of the Polymer}

\section{Morphology characterization}

The surface morphology of NIP, MIP, and MeIP was characterized by SEM with 10,000 times of magnification (Fig. 2). As seen on the SEM image, remarkable differences in the morphologies of the polymers were considered, and a porous surface could be manifestly observed in MeIP, whereas the surface of MIP was bulky because of the presence of meropenem in the formation of the polymer. The more porous surface of MeIP supports the higher adsorption of the analyte, meropenem.

\section{FTIR analysis}

To confirm the functional group of the polymers, characterization using FTIR analysis was done. As seen in the spectrum Fig. 3, no peak was found around 1,600 $\mathrm{cm}^{-1}$, corresponding to the peak for the vinyl group. The possible explanation is that all of vinyl was involved in the polymerization. At $3,400-3,450 \mathrm{~cm}^{-1}$, a broad peak of $\mathrm{OH}$ was found in the MIP spectrum, which is different in sharpness compared to NIP and MeIP corresponding to the presence of assembled-OH from a monomer and the template (meropenem) in the process before extraction. Since the OH peak was only from the monomer, it was found that the peak was not broad after the template extraction. The peaks in this region were similar for NIP and MeIP. The presence of meropenem in the spectrum of MIP was detected at the wavenumber of $1,018 \mathrm{~cm}^{-1}$ and $950 \mathrm{~cm}^{-1}$, where these peaks come from $\beta$-lactam for $\mathrm{C}-\mathrm{H}$ stretching and $\mathrm{C}-\mathrm{N}$ stretching [15].

\section{Thermal characterization}

The thermal characterization was accomplished to examine the stability of the material [16-17], illustrated in Fig. 4. All polymers smoothly decomposed from 100 to $200{ }^{\circ} \mathrm{C}$ because the excess of solvent loss and the complex decomposition process started at $270{ }^{\circ} \mathrm{C}$. As seen in the thermogram, MIP was decomposed at $340^{\circ} \mathrm{C}$,

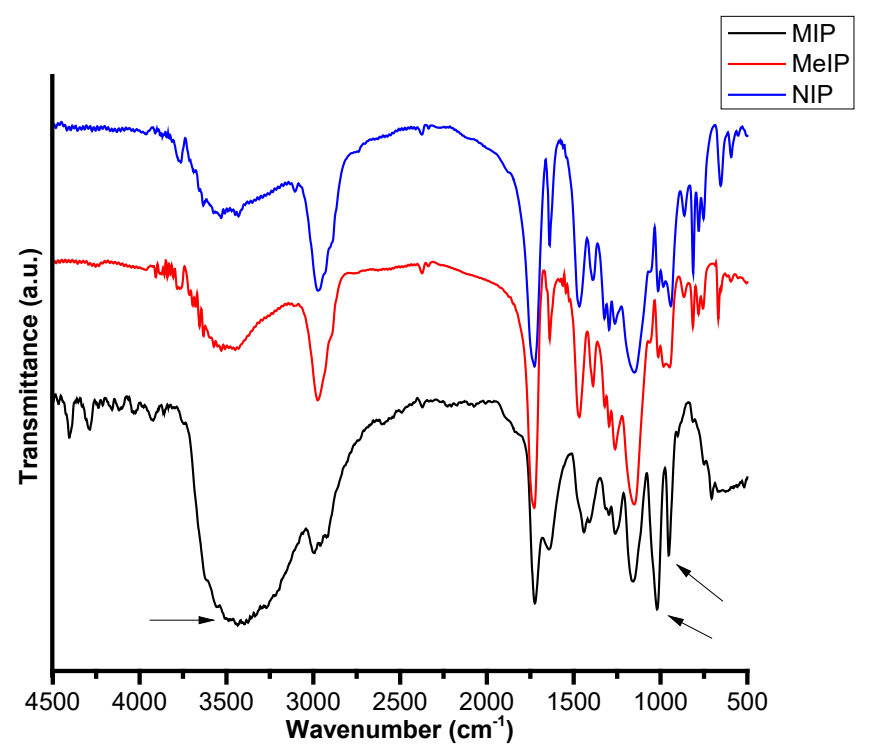

Fig 3. FTIR spectrum for NIP, MIP, and MeIP 


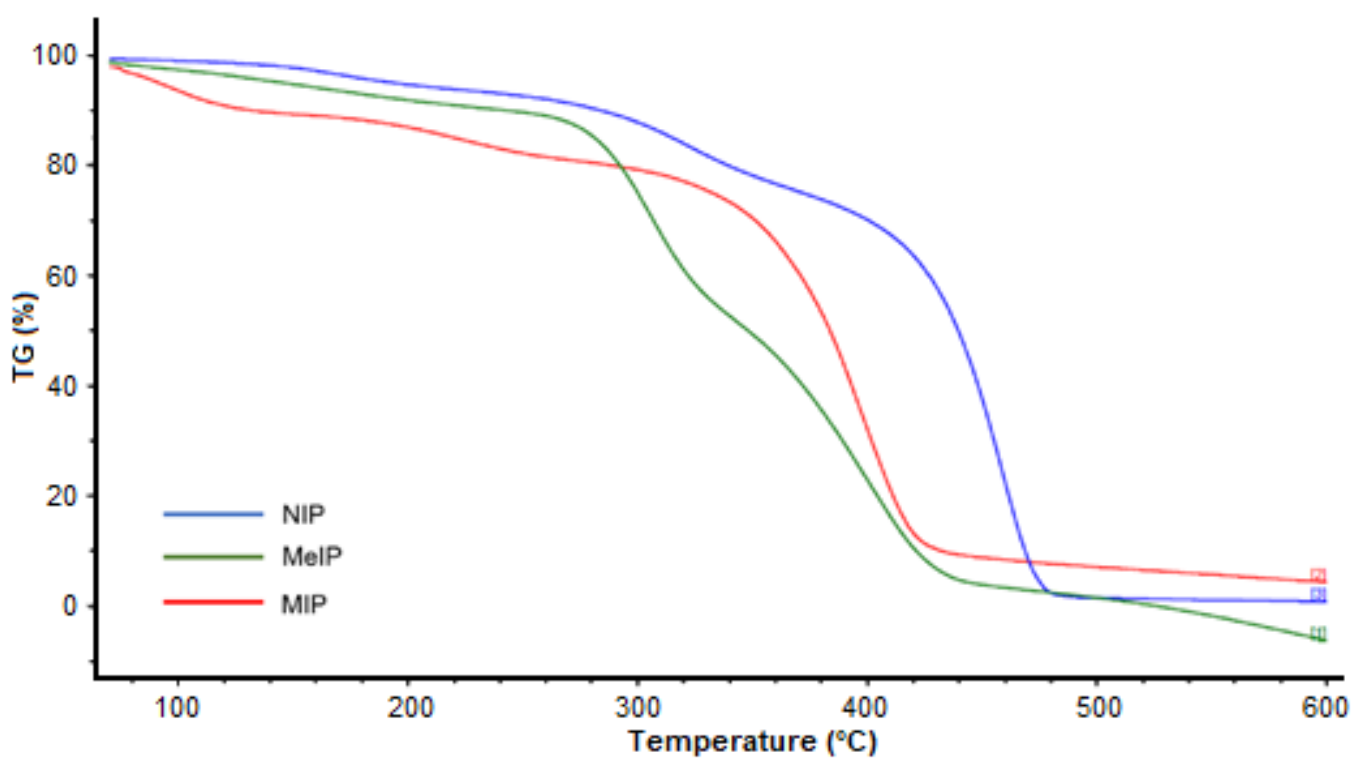

Fig 4. The thermogram of NIP, MIP, and MeIP

whereas the decomposition of NIP and MeIP started at a temperature under $340{ }^{\circ} \mathrm{C}$. The possible reason for this phenomenon is that MIP had molecules of meropenem, which MeIP and NIP did not have, so the presence of meropenem leads to the necessity of higher temperature for its decomposition. Also, the difference in weight loss between MIP and NIP may be attributed to the temperature of meropenem degradation., which made the grafting density of the polymer different during polymerization.

\section{BET analysis for specific surface area}

Since specific surface area and pore size influenced the efficiency of MISPE adsorption, the parameters were obtained using a BET analysis. From Table 2, it can be seen that the pore diameter of MeIP was smaller, but the specific area and the pore volume were larger than those of NIP. Compared with NIP, MeIP has more pores. This phenomenon strongly indicated the effect of imprinting on polymerization. From the data, MeIP could provide more accessible cavities and binding sites for the target analyte than NIP. Therefore, the MeIP synthesized has benefited

Table 2. The results of BET analysis for NIP and MeIP

\begin{tabular}{lccc}
\hline Polymer & $\begin{array}{c}\text { Specific area, } \\
\mathrm{m}^{2 /} \mathrm{g}\end{array}$ & $\begin{array}{c}\text { Pore volume } \\
(\mathrm{cc} / \mathrm{g})\end{array}$ & $\begin{array}{c}\text { Pore diameter } \\
\left(\mathrm{A}^{\mathrm{o}}\right)\end{array}$ \\
\hline $\mathrm{NIP}$ & 4.643 & $1.83 \times 10^{2}$ & 78.69 \\
$\mathrm{MeIP}$ & 47.08 & $6.43 \times 10^{2}$ & 27.27 \\
\hline
\end{tabular}

from the conduction of interaction and has more accessibility to the adsorbate.

\section{Adsorption Test}

\section{Effect of $\mathrm{pH}$}

Owing to the presence of $\mathrm{OH}^{-}, \mathrm{H}^{+}$, and $\mathrm{NH}$ in the structure of meropenem, as well as the $\mathrm{pH}$ value of meropenem $(\mathrm{pKa} 1=2.9 ; \mathrm{pKa} 2=7.4)[18]$, the $\mathrm{pH}$ may influence its ionic form. That is why $\mathrm{pH}$ is important to be considered in studying the adsorption behavior of MA as the polymer has pKa of 5.4 [19]; thus, the high adsorption at $\mathrm{pH} 3$ could be caused by the electrostatic interaction between meropenem in the anionic state and MA in the protonated state. The presence of a cavity also supported this high value. However, in $\mathrm{pH} 4$, the adsorption was decreased because the positive charge on the MA surface was decreased. By contrast, when the meropenem met its isoelectric point of approximately 5.15 [20], it was attached to the sorbent surface by partition mechanism [21]. Further, the adsorption dropped with increasing $\mathrm{pH}$ because of the negative charges on both the sorbent surface and meropenem. Thus, the interaction was electrostatic repulsion instead. Predominantly, the adsorption of meropenem using MeIP resulted in a higher value than that using NIP because of by the cavity in MeIP. Fig. 5 indicated the decrease of adsorption $(n=3)$ because adsorption was 
dependent on not only the charge of the analyte but also the charge of the surface of the functional monomer, MA [22].

\section{Effect of mass of the sorbent}

The mass of the sorbent must affect the adsorption capacity because it represents the amount of the sorbent that can adsorb the analyte. Fig. 6 illustrates the dependence of the adsorption capacity on the mass of the sorbent $(n=3)$. It can be stated that increasing the polymer mass increased the adsorption of meropenem. However, the adsorption remained constant when the mass of the sorbent was over $25 \mathrm{mg}$. This can be attributed to the saturation of the active site on the sorbent [23].

MeIP gave a higher adsorption capacity than that of NIP at the same mass considering the active site of the imprinting molecule. Meanwhile, the adsorption on NIP was caused only by the unspecific pore in the surface, contrary to the adsorption on MeIP, which is mainly caused by the active site. It can be concluded that the imprinting factor successfully gained.

\section{Effect of contact time}

In the adsorption process, contact time is typically investigated in a different span of 1 to $10 \mathrm{~h}$. In Fig. 7, $4 \mathrm{~h}$ contact time gives the maximum adsorption of meropenem. The adsorption of meropenem onto MeIP always gave a higher value than that onto NIP because the active site on MeIP offered more adsorption than the

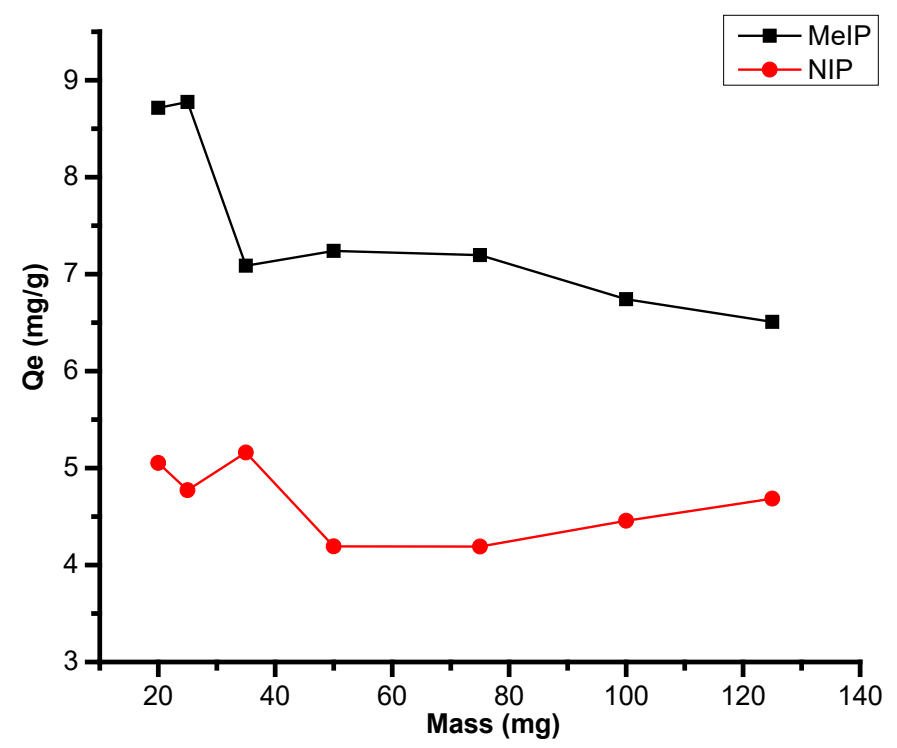

Fig 6. Effect of mass of the sorbent on adsorption capacity surface of NIP, which was only caused by the unspecific pore of NIP. However, MeIP met the constant state when the contact time was over $4 \mathrm{~h}$. This indicated that the analyte had covered up the MeIP surface. Thus, the surface had been saturated and could not draw more analytes [24].

From Fig. 8, the kinetics model of meropenem adsorption onto MeIP fit to a pseudo-second-order mechanism that had a regression value of 0.8524 . The adsorption involved electron exchange between the adsorbent (MeIP) and the analyte (meropenem). The

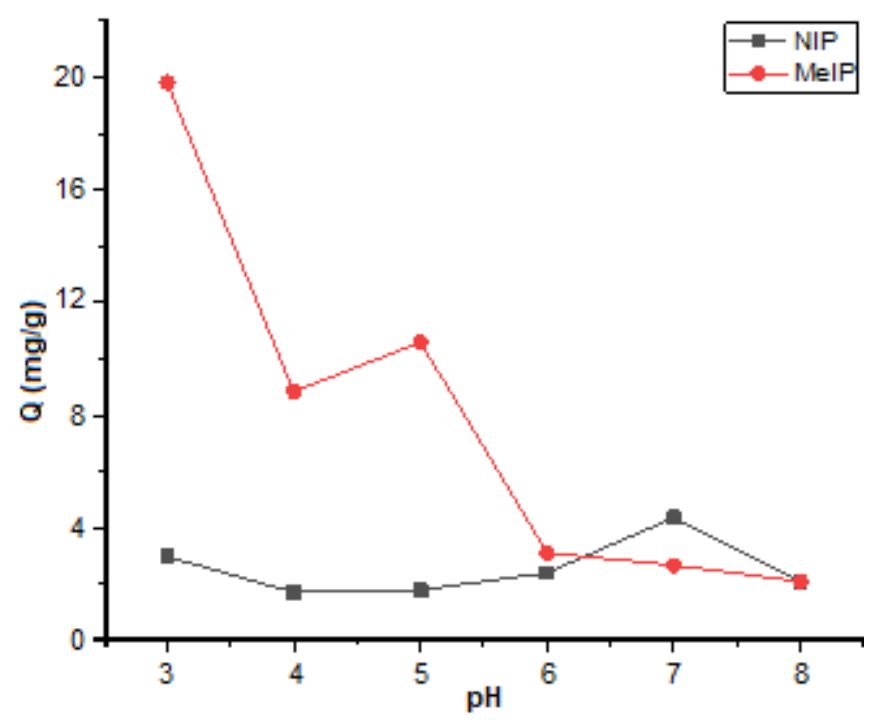

Fig 5. pH effect to adsorption capacity

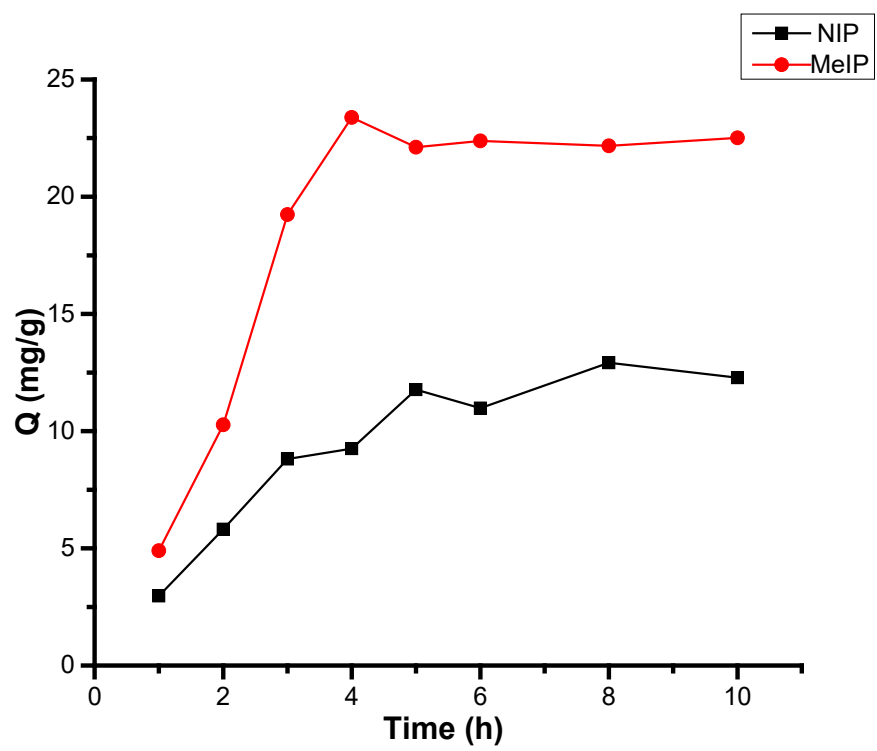

Fig 7. Effect of contact time 

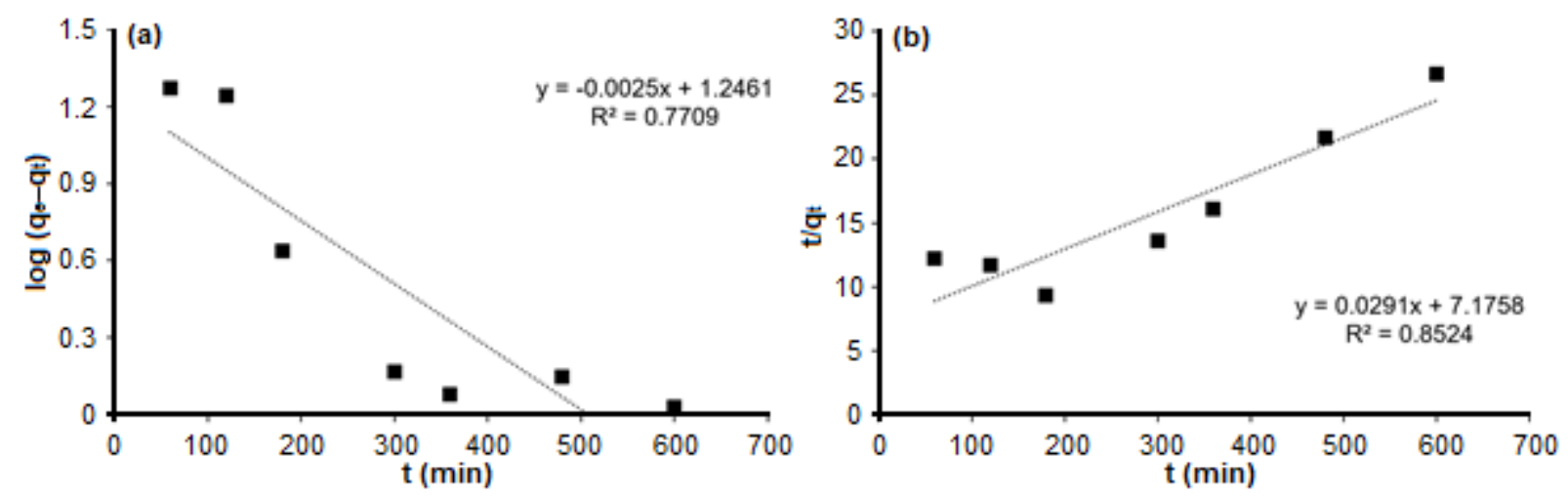

Fig 8. The (a) pseudo-first order and (b) pseudo-second-order kinetics model of the meropenem adsorption by using MeIP

pseudo-second order assumes that there is no desorption, so the back reaction is negligible. The concentration of the analyte involved in adsorption was considered to be stable because concentrations observed were those in the adsorbent, not in the analyte solution [25].

From Fig. 8, the kinetics model of meropenem adsorption onto MeIP fit to a pseudo-second-order mechanism that had a regression value of 0.8524 . The adsorption involved electron exchange between the adsorbent (MeIP) and the analyte (meropenem). The pseudo-second order assumes that there is no desorption, so the back reaction is negligible. The concentration of the analyte involved in adsorption was considered to be stable because concentrations observed were those in the adsorbent, not in the analyte solution [25].

\section{Effect of initial concentration}

As presented in Fig. 9, the adsorption capacity increased as the initial concentration increased until the concentration of $75 \mathrm{mg} / \mathrm{L}(\mathrm{n}=3)$. The adsorption capacity remained stable, implying that equilibrium had been reached. MeIP capacity was higher than NIP capacity at any concentration, indicating that binding affinity of meropenem in the sorbent (MeIP) had been successfully obtained.

In this work, the adsorption isotherm was determined by the amount of the analyte after the adsorption process to determine the analyte adsorbed. Langmuir and Freundlich isotherm models were examined in this work. Langmuir assumes the monolayer adsorption; the active site in the surface of adsorbent has homogen energy of adsorption at any area in the surface [26]. Meanwhile, $\mathrm{K}$, in the isotherm model of Langmuir and Freundlich, depicts the amount of binding capacity between the analyte and the surface of the adsorbent (MeIP) [26]. The equilibrium data of MeIP were fitted to the Langmuir and Freundlich isotherm models. The correlation coefficient $\left(\mathrm{R}^{2}\right)$ is used to study the applicability of the isotherm models to the adsorption behaviors.

The adsorption isotherm constants of MeIP are listed in Table 3. Furthermore, non-linear regression is used to compare the Langmuir isotherm model with the Freundlich isotherm model for adsorption of meropenem onto MeIP, and the results are illustrated in Fig. 10. The Langmuir isotherm model is used to describe monolayer

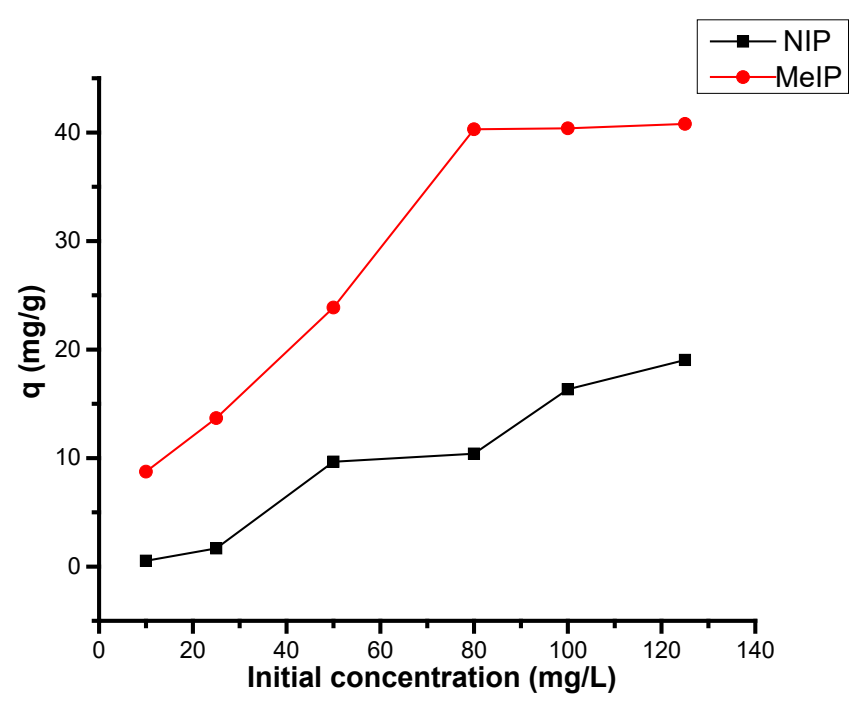

Fig 9. Effect of initial concentration 
Table 3. Parameters of isotherms

\begin{tabular}{ccccc}
\hline \multirow{2}{*}{$\begin{array}{c}\text { Q } \\
\mathrm{max}\end{array} \mathrm{g} / \mathrm{g}$} & \multicolumn{2}{c}{ Langmuir Isotherm } & \multicolumn{2}{c}{ Freundlich Isotherm } \\
\cline { 2 - 5 } & $\mathrm{K}_{\mathrm{L}}$ & $\mathrm{R}^{2}$ & $\mathrm{~K}_{\mathrm{F}}$ & $\mathrm{R}^{2}$ \\
\hline 51.963 & 0.069 & 0.7963 & 8.437 & 0.9379 \\
\hline
\end{tabular}

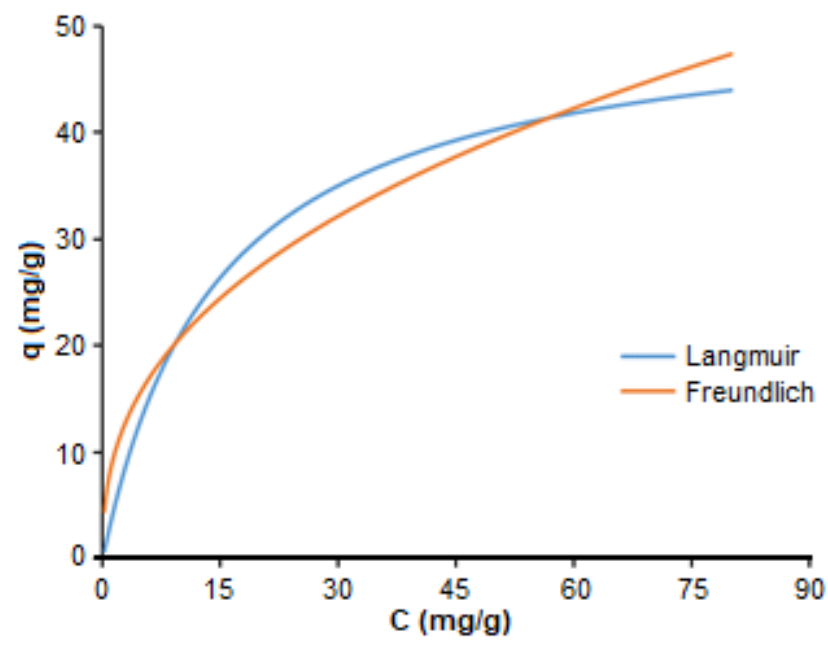

Fig 10. Isotherm model of the adsorption of meropenem using MeIP

adsorption on the adsorbent surface with limited identified sites [26]. The linear form is expressed by Eq. (6), and the Freundlich isotherm model is given as Eq. (7). An empirical equation is used to describe the adsorption process [27].

$\mathrm{C}_{\mathrm{e}} / \mathrm{q}_{\mathrm{e}}=\mathrm{C}_{\mathrm{e}} / \mathrm{q}_{\mathrm{m}}+1 /\left(\mathrm{q}_{\mathrm{m}} \mathrm{KL}\right)$

$\ln \mathrm{q}_{\mathrm{e}}=\ln \mathrm{C}_{\mathrm{e}} / \mathrm{n}+\ln \mathrm{KF}$

From Fig. 10, the data calculated was presented in Table 3. It can be confirmed that the adsorption of meropenem followed the Freundlich model.

\section{Selectivity test}

The imprinting factor of meropenem was compared to those of other competitive compounds to determine the selectivity. The competitive compounds selected were cefadroxil, penicillin G, amoxicillin, and curcumin. Cefadroxil, penicillin G, and amoxicillin (see Fig. 11) were chosen because of the similarity of B-lactam in their main structure; curcumin was also investigated because its selectivity had to be examined as it was often prescribed together with antibiotics on therapy. The IF value is given in Fig. 12. The result indicated that the adsorption amounts of penicillin $\mathrm{G}$ and cefadroxil were high; this resulted from their structural similarity to meropenem. By contrast, MeIP had low affinity for amoxicillin; this might be because the optimum condition ( $\mathrm{pH}$ and employed solvent) obtained for extraction of meropenem was not suitable for amoxicillin.

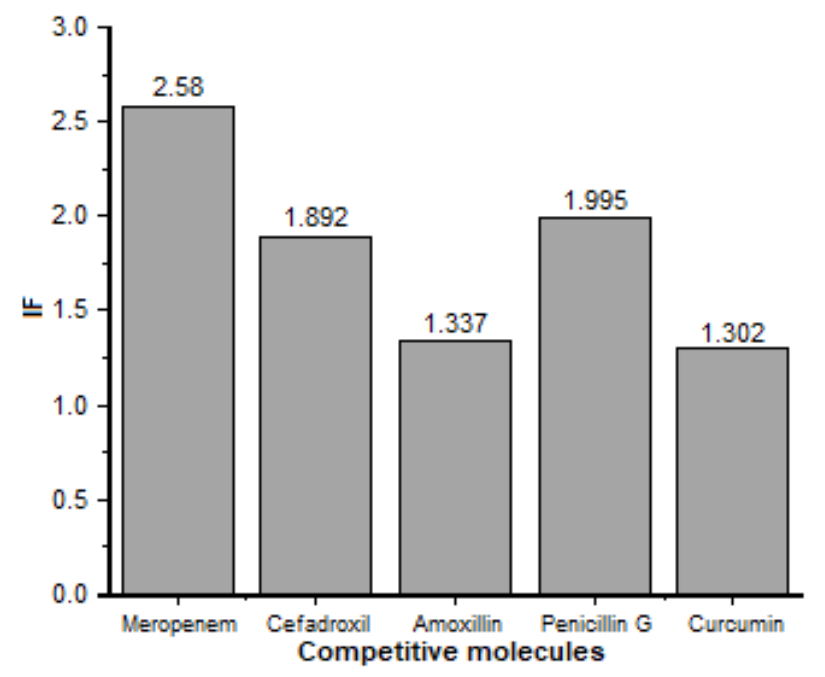

Fig 12. IF of meropenem and competitive molecule<smiles>CC1=C(C(=O)O)N2C(=O)[C@H](NC(=O)[C@H](N)c3ccc(O)cc3)[C@H]2SC1</smiles>

(d)<smiles>CC1(C)S[C@H]2C(NC(=O)[C@@H](N)c3ccc(O)cc3)C(=O)N2[C@H]1C(=O)O</smiles>

(c)

(e)<smiles>CC1(C)S[C@@H]2C(NC(=O)Cc3ccccc3)C(=O)N2[C@H]1C(=O)O</smiles><smiles>CC1C(S[C@@H]2CNC(C(=O)N(C)C)C2)=C(C(=O)O)N2C(=O)[C@H]([C@@H](C)O)[C@H]12</smiles>

Fig 11. The chemical structure of competitive compounds: (a) cefadroxil, (b) amoxicillin, (c) penicillin $G$ and (d) curcumin (e) meropenem 
MeIP also had affinity to curcumin, a supplement compound that is given mostly with antibiotics; however, they have a different structure to that of meropenem. This might be caused by the unselective pores in the surface of the polymer, which accommodates the size of the molecule of curcumin. In the calculation of the imprinting factor, IF, the adsorption capacity of MeIP was higher than that of NIP, because of the absence of binding sites in NIP that also caused low adsorption and affinity.

\section{Thermodynamics of adsorption}

The common thermodynamic parameters, i.e., the standard enthalpy change $\left(\Delta \mathrm{H}^{\circ}\right)$, the standard free energy change $\left(\Delta \mathrm{G}^{\circ}\right)$ and the standard entropy change $\left(\Delta S^{\circ}\right)$, were also determined in this study. Those were calculated using Eq. (8) and (9).

$\ln \mathrm{K}_{\mathrm{c}}=-\Delta \mathrm{H}^{\circ} / \mathrm{RT}+\Delta \mathrm{S}^{\circ} / \mathrm{R}$

$\Delta \mathrm{G}^{\circ}=\mathrm{RT} \ln \mathrm{K}_{\mathrm{c}}$

$\mathrm{K}_{\mathrm{c}}(\mathrm{mL} / \mathrm{g})$ is a distribution constant and can be calculated by plotting $\ln \left(\mathrm{q}_{\mathrm{e}} / \mathrm{C}_{\mathrm{e}}\right)$ versus $\mathrm{q}_{\mathrm{e}}$ and extrapolating $\mathrm{q}_{\mathrm{e}}$ to zero. The value of $\mathrm{K}_{\mathrm{c}}$ is the intercept of the straight line; $\mathrm{T}$ is the absolute temperature $(\mathrm{K})$, and $\mathrm{R}$ is the gas constant $(8.3145 \mathrm{~J} /(\mathrm{mol} \mathrm{K}))$. The obtained thermodynamic parameters for meropenem-MeIP for the adsorption process are listed in Table 4. A negative $\Delta \mathrm{G}^{\circ}$ value indicated that the adsorption of meropenem onto MeIP was spontaneous within the evaluated temperature range. A negative value of $\Delta \mathrm{H}^{\circ}$ confirmed that the adsorption process was exothermic. Therefore, decreasing the temperature can favor the adsorption of meropenem onto MeIP [28]. The more the meropenem molecules adsorbed onto the MeIP surface, the more solvent molecules surrounded meropenem molecules. Thus, the degree of freedom to meropenem molecules was decreased [29]. A negative value of $\Delta S^{\circ}$ suggested that there was low-binding randomness at the solid-solution interface [28].

\section{MISPE Analysis}

A $50 \mathrm{mg}$ amount of imprinted polymer was packed into an empty SPE cartridge of a $1 \mathrm{~mL}$ analyte solution with frits at the bottom. The bleeding of the residual template from the polymer was checked by washing the MISPE cartridge with acetonitrile:water $(95: 5 \mathrm{v} / \mathrm{v})$. The chromatogram was free of meropenem. For the first step of extraction of meropenem, MISPE cartridges were conditioned with $3 \mathrm{~mL}$ of methanol and $3 \mathrm{~mL}$ of HPLC grade water, to wet the polymer completely before its usage; then, $1 \mathrm{~mL}$ of $40 \mathrm{mg} / \mathrm{L}$ of the meropenem solution was passed through at $0.25,0.55$, and $3 \mathrm{~mL} / \mathrm{min}$. After loading, the polymer was washed with acetonitrile. The target analyte was eluted from the polymer with $1 \mathrm{~mL}$ of methanol:acetic acid $(80: 20 \mathrm{v} / \mathrm{v})$. The effect of the flow rate and treatment before elution applied on extraction is presented in Table 5 .

The lower flow rate applied meant the longer time of the analyte in contact with the polymer that led to more the analyte being adsorbed. As seen from the table, although the polymer and the analyte were in the same cartridge but made no contact, it did not give an advantage for the adsorption.

Reusability study of the adsorbent is one of important parameter that can show an advantage of MIS-PE application. In this study, the investigation of MeIP reusability $(n=3)$ gave the result as shown in Fig. 13.

Further, for the SPE study, we investigated the selectivity of the MeIP to amoxicillin. $50 \mathrm{mg} / \mathrm{L}$ for each meropenem-amoxicillin passed through the $1 \mathrm{~mL}$ SPE column with a flow rate of $0.25 \mathrm{~mL} / \mathrm{min}$. According to the literature, the modified optimum eluent was water:methanol:phosphoric acid: triethylamine (842:150:4:4 v/v/v), and the $\mathrm{pH}$ adjusted to 4 was the best

Table 4. Thermodynamic parameters of meropenemMeIP

\begin{tabular}{cccc}
\hline $\mathrm{T}(\mathrm{K})$ & $\Delta \mathrm{H}^{\circ}(\mathrm{kJ} / \mathrm{mol})$ & $\Delta \mathrm{G}^{\circ}(\mathrm{kJ} / \mathrm{mol})$ & $\Delta \mathrm{S}^{\circ}(\mathrm{J} /(\mathrm{mol} \mathrm{K}))$ \\
\hline 298 & & -26.229 & \\
313 & -71.465 & -23.952 & -151.797 \\
328 & & -21.675 & \\
\hline
\end{tabular}

Table 5. The effect of the flow rate applied $(\mathrm{n}=3)$

\begin{tabular}{cc}
\hline Flow rate $(\mathrm{mL} / \mathrm{min})$ & Adsorption $(\%)$ \\
\hline 0.25 & 82.59 \\
0.55 & 77.01 \\
3.00 & 28.66 \\
Left for $5 \mathrm{~min}$ & 26.11 \\
Left for $10 \mathrm{~min}$ & 26.02 \\
\hline
\end{tabular}




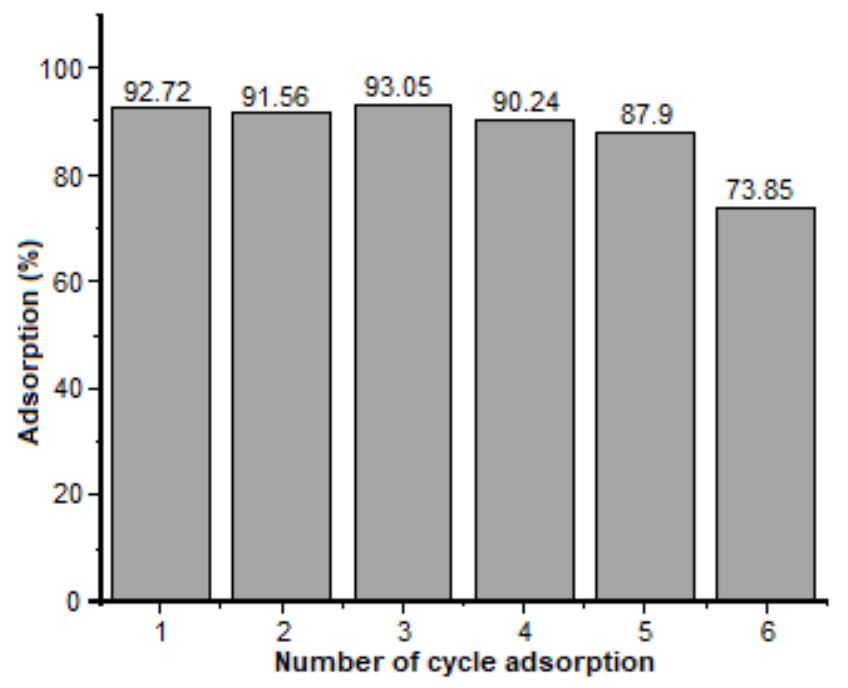

Fig 13. Reusability of MeIP for meropenem adsorption

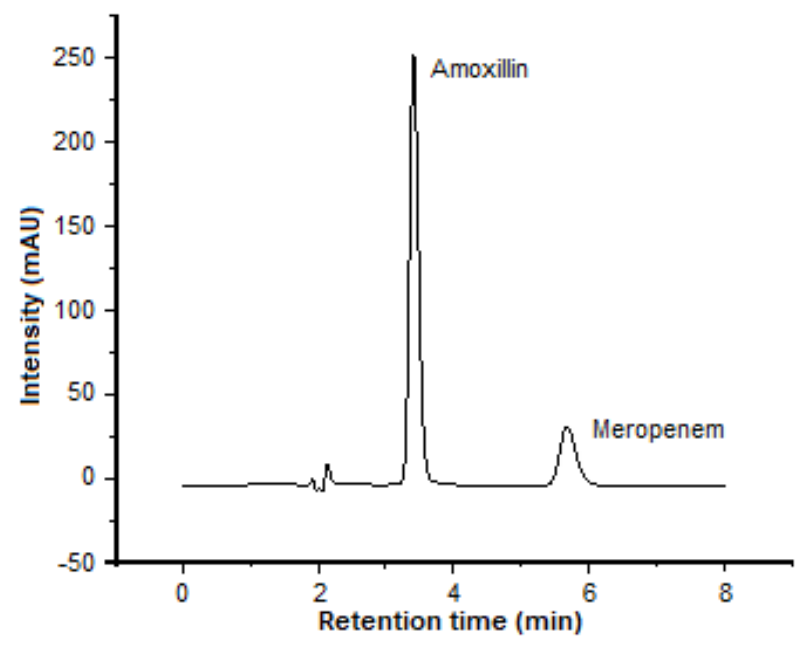

Fig 14. Chromatogram of meropenem-amoxicillin separation on SPE

Table 6. Summary of meropenem-amoxicillin adsorption on SPE $(n=3)$

\begin{tabular}{ccc}
\hline & meropenem & amoxicillin \\
\hline $\mathrm{C}_{\text {initial }}(\mathrm{mg} / \mathrm{L})$ & 50 & 50 \\
$\mathrm{C}_{\text {after }}(\mathrm{mg} / \mathrm{L})$ & 7.01 & 28.64 \\
Adsorption $(\%)$ & 85.98 & 42.72 \\
$\mathrm{C}_{\text {found }}(\mathrm{mg} / \mathrm{L})$ & 35.25 & 17.75 \\
Recovery $(\%)$ & 81.12 & 83.09 \\
\hline
\end{tabular}

for the separation for meropenem-amoxicillin in HPLC [30]. The separation chromatogram and the recovery can be seen in Fig. 14 and Table 6, respectively; they indicate that the adsorption of MeIP to meropenem was two times higher than that to amoxicillin.

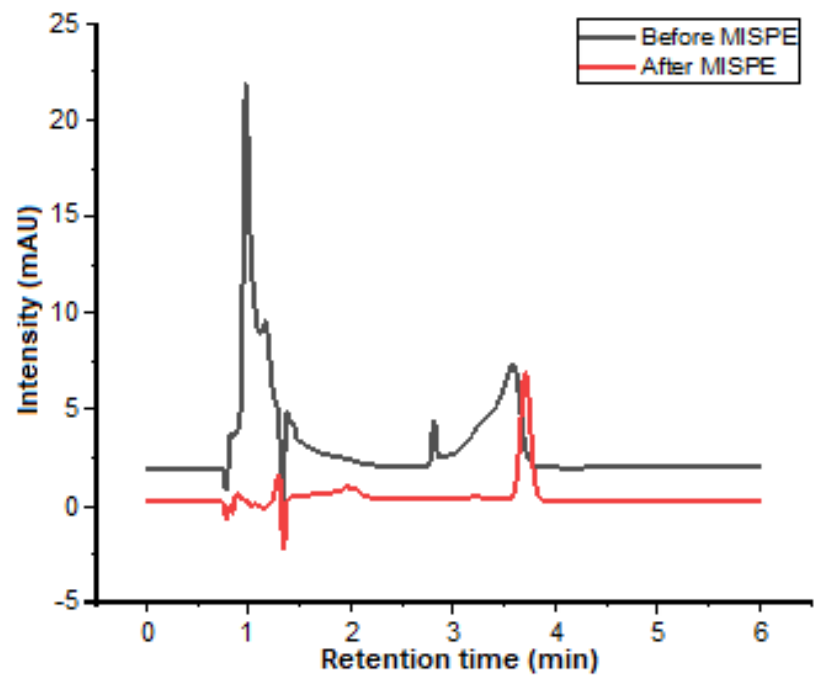

Fig 15. Chromatograms of meropenem before and after MISPE

Table 7. Determination of meropenem in plasma using $\operatorname{MISPE}(\mathrm{n}=3)$

\begin{tabular}{ccc}
\hline Spiked concentration & Adsorption (\%) & Recovery (\%) \\
\hline $40 \mathrm{mg} / \mathrm{L}$ & $76.85 \pm 6.18$ & $78.52 \pm 2.71$ \\
\hline
\end{tabular}

\section{Sample Preparation}

The fresh human blood plasma was obtained from Red Cross Indonesia, Bandung region, Indonesia. Chromatograms of the analyte before and after MISPE application are presented in Fig. 15. The percentage of adsorption and recovery of meropenem are listed in Table 7. The percentage of adsorption seemed to be stable in three times of repetition, referred to the stability use (reusability) of the synthesized polymer.

\section{- CONCLUSION}

A novel molecular imprinted polymer (MeIP) for extraction and identification of meropenem using a polar solvent was successfully prepared. In this study, MeIP was prepared to quantify meropenem in human blood plasma. An MISPE procedure was applied by combining it with HPLC detection. This study has demonstrated good performance of adsorption capacity compared to NIP, high selectivity of competitive molecules, and good reusability of polymers to meropenem. These polymer particles can be promising materials for SPE and column packing materials. 


\section{- AUTHOR CONTRIBUTIONS}

LS conducted the experiment and analysis. MAZ, $\mathrm{MB}, \mathrm{AA}$ examined the experimental and analytical data. LS wrote the original manuscript. All authors agreed to the final version of this manuscript.

\section{- REFERENCES}

[1] Mendez, A.S.L., Steppe, M., and Schapoval, E.E.S., 2003, Validation of HPLC and UV spectrophotometric methods for the determination of meropenem in pharmaceutical dosage form, $J$. Pharm. Biomed. Anal., 33 (5), 947-954.

[2] Baldwin, C.M., Lyseng-Williamson, K.A., and Keam, S.J., 2008, Meropenem: A review of its use in the treatment of serious bacterial infections, Drugs, 68 (6), 803-838.

[3] Nicolau, D.P., 2008, Pharmacokinetic and pharmacodynamic of meropenem, Clin. Infect. Dis., 47 (Suppl. 1), S32-S40.

[4] Beltran, A., Marcé, R.M., Cormack, P.A.G., Sherrington, D.C., and Borrull, F., 2008, Selective solid-phase extraction of amoxicillin and cephalexin from urine samples using a molecularly imprinted polymer, J. Sep. Sci., 31 (15), 2868-2874.

[5] Tuerk, J., Reinders, M., Dreyer, D., Kiffmeyer, T.K., Schmidt, K.G., and Kuss, H.M., 2006, Analysis of antibiotics in urine and wipe samples from environmental and biological monitoringComparison of HPLC with UV-, single MS- and tandem MS-detection, J. Chromatogr. B, 831 (1), 7280.

[6] Soran, M.L., Lung, I., Opriş, O., Floare-Avram, V., and Coman, C., 2017, Determination of antibiotics in surface water by solid-phase extraction and highperformance liquid chromatography with diode array and mass spectrometry detection, Anal. Lett., 50 (7), 1209-1218.

[7] Oyedeji, A.O., Msagati, T.A.M., Williams, A.B., and Benson, N.U., 2020, Solid-phase extraction and high performance liquid chromatography with diode array detection method for the determination of antibiotic residues in poultry tissues, Chem. Data Collect., 25, 100312.
[8] Amlashi, H.S., Daryasari, A.P., and Soleimani, M., 2019, Molecularly imprinted polymer solid phase extraction followed by high-performance liquid chromatography as an efficient and sensitive technique for determination of meropenem in human plasma and urine, S. Afr. J. Chem., 72, 32-39.

[9] Chow, A.L.J., and Bhawani, S.A., 2016, Synthesis and characterization of molecular imprinting polymer microspheres of cinnamic acid: Extraction of cinnamic acid from spiked blood plasma, Int. J. Polym. Sci., 2016, 2418915.

[10] Duan, Z.J., Fan, L.P., Fang, G.Z., Yi, J.H., and Wang, S., 2011, Novel surface molecularly imprinted solgel polymer applied to the online solid phase extraction of methyl-3-quinoxaline-2-carboxylic acid and quinoxaline-2-carboxylic acid from pork muscle, Anal. Bioanal. Chem., 401 (7), 2291-2299.

[11] Kryscio, D.R., and Peppas, N.A., 2012, Surface imprinted thin polymer film systems with selective recognition for bovine serum albumin, Anal. Chim. Acta, 718, 109-115.

[12] Du, W., Zhou, H., Luo, Z., Zheng, P., Guo, P., Chang, R., Chang, C., and Fu, Q., 2014, Selective determination of penicillin $\mathrm{G}$ from tap water and milk samples using surface molecularly imprinted polymers as solid-phase extraction sorbent, Mol. Imprinting, 2 (1), 18-29.

[13] Yan, H., and Row, K.H., 2006, Characteristic and synthetic approach of molecularly imprinted polymer, Int. J. Mol. Sci., 7 (5), 155-178.

[14] Jin, Y.F., Zhang, Y.J., Zhang, Y.P., Chen, J., Zhou, X.M., and Bai, L.Y., 2013, Synthesis and evaluation of molecularly imprinting polymer for the determination of the phthalate esters in the bottled beverages by HPLC, J. Chem., 2013, 903210.

[15] Cielecka-Piontek, J., Paczkowska, M., Lewandowska, K., Barszcz, B., Zalewski, P., and Garbacki, P., 2013, Solid-state stability study of meropenem - solutions based on spectrophotometric analysis, Chem. Cent. J., 7, 98 .

[16] Barros, L.A., Custodio, R., and Rath, S., 2016, Design of a new molecularly imprinted polymer selective for hydrochlorothiazide based on 
theoretical predictions using Gibbs free energy, $J$. Braz. Chem. Soc., 27 (12), 2300-2311.

[17] Triadhi, U., Zulfikar, M.A., Setiyanto, H., and Amran, M.B., 2018, Effects of (monomer - crosslinker - initiator) composition during non imprinted polymers synthesis for catechin retention, J. Phys.: Conf. Ser., 1013, 012192.

[18] Tomasello, C., Leggieri, A., Cavalli, R., Di Terri, G., and D'Avolio, A., 2015, In vitro stability evaluation of different pharmaceutical products containing meropenem, Hosp. Pharm., 50 (4), 296-303.

[19] Marić, M., Zhang, C., and Gromadzki, D., 2017, Poly(methacrylic acid-ran-2-vinylpyridine) statistical copolymer and derived dual pH-temperature responsive block copolymers by nitroxide-mediated polymerization, Processes, 5 (1), 7.

[20] Roth, T., Fiedler, S., Mihai, S., and Parsch, H., 2016, Determination of meropenem levels in human serum by high-performance liquid chromatography with ultraviolet detection, Biomed Chromatogr., 31 (5), e3880.

[21] Khan, S.A., Siddiqui, M.F., and Khan, T.A., 2020, Synthesis of poly(methacrylic acid)/montmorillonite hydrogel nanocomposite for efficient adsorption of amoxicillin and diclofenac from aqueous environment: Kinetic, isotherm, reusability, and thermodynamic investigations, ACS Omega, 5 (6), 2843-2855.

[22] Qiu, L., Jaria, G., Gil, M.V., Feng, J., Dai, Y., Esteves, V.I., Otero, M., and Calisto, V., 2020, Core-shell molecularly imprinted polymers on magnetic yeast for the removal of sulfamethoxazole from water, Polymers, 12 (6), 1385.

[23] Sadeghi, S., and Jahani, M., 2013, Selective solidphase extraction using molecular imprinted polymer sorbent for the analysis of florfenicol in food samples, Food Chem., 141 (2), 1242-1251.

[24] Serunting, M.A., Rusnadi, R., Setyorini, D.A., and Ramadan, B.S., 2018, An effective cerium(III) ions removal method using sodium alginate-coated magnetite $\left(\mathrm{Alg}-\mathrm{Fe}_{3} \mathrm{O}_{4}\right)$ nanoparticles, J. Water Supply: Res. Technol. - AQUA, 67 (8), 754-765.

[25] Li, Y., Xiao, H., Pan, Y., and Wang, L., 2018, Novel composite adsorbent consisting of dissolved cellulose fiber/microfibrillated cellulose for dye removal from aqueous solution, ACS Sustainable Chem. Eng., 6 (5), 6994-7002.

[26] Ayawei, N., Ebelegi, A.N., and Wankasi, D., 2017, Modelling and interpretation of adsorption isotherms, J. Chem., 2017, 3039817.

[27] Carvalho, M.N., de Abreu, C.A.M., Benachour, M., Sales, D.C.S., Baraúna, O.S., and da Motta Sobrinho, M.A., 2012, Applying combined LangmuirFreundlich model to the multi-component adsorption of BTEX and phenol on smectite clay, Adsorpt. Sci. Technol., 30 (8-9), 691-699.

[28] Cao, Y., Xu, W., Wu, X., Li, Y., Li, H., and Huang, W., 2013, Synthesis of a molecularly imprinted polymer on silica-gel surfaces for the selective adsorption of indole from fuel oil, Adsorpt. Sci. Technol., 31 (6), 489-502.

[29] Huang, W., Li, H., Xu, W., Zhou, W., Zhou, Z., and Yang, W., 2012, Selective adsorption of dibenzothiophene using magnetic molecularly imprinted polymers, Adsorpt. Sci. Technol., 30 (4), 331-343.

[30] Douša, M., and Hosmanová, R., 2004, Rapid determination of amoxicillin in premixes by HPLC, J. Pharm. Biomed. Anal., 37 (2), 373-377. 